\title{
ABAC internacional y su contraparte mexicana
}

$\mathrm{E}$ stas son básicamente algunas notas que tienen por objeto describir brevemente qué es $\mathrm{ABAC}$, cómo está integrado, cuáles son sus principales lineamientos y cuál es su papel como parte de APEC. Se presenta también aquí, quiénes lo integran por parte de México y lo que se espera de ellos en el marco de la reunión de APEC 2002 a realizarse en nuestro país.

\section{ABAC dentro de APEC}

ABAC (APEC Business Advisory Council, por sus siglas en inglés), es el Consejo Asesor Empresarial de APEC, y representa la 'voz oficial' del sector privado dentro de este organismo. Fue establecido por los líderes de APEC en la reunión cumbre celebrada en Osaka, Japón, en noviembre de 1995, para formalizar la participación del sector privado en el interior del mismo. Sus principios básicos son:

- Asesorar a los líderes de APEC sobre la implementación de la agenda de éste y de otros asuntos específicos prioritarios para el sector.

- Apoyar a la APEC cuando requiera de información sobre aspectos relacionados con los negocios y sobre perspectivas de cooperación en áreas específicas.

* Investigador del Departamento de Estudios del Pacífico de la Universidad de Guadalajara.
ABAC está integrado por tres prominentes empresarios representantes de cada economía integrante de APEC, quienes son nombrados por sus respectivos gobernantes. El presidente de ABAC es nombrado por el presidente de APEC por un período similar al de éste, y es apoyado en sus tareas por dos vicepresidentes -el último en ocupar la presidencia y el próximo en ocuparla-, así como por los presidentes de los diversos comités y grupos de trabajo.

Cada año, ABAC presenta un informe anual a los líderes de APEC en el que establece sus puntos de vista y fija su postura con respecto a la agenda del organismo, aunque siempre en concordancia con sus preceptos. Además, participa en las reuniones clave de los ministros y funcionarios de APEC a fin de promover las inversiones entre los países miembros.

ABAC se reúne tres o cuatro veces por año en las diferentes economías pertenecientes al organismo, con el propósito de discutir y llegar a acuerdos sobre sus prioridades y recomendaciones para los líderes de APEC, así como en otras áreas de interés común. Los intereses y prioridades de ABAC son determinadas cada año por sus miembros en reuniones plenarias, y sus recomendaciones son retomadas para su implementación tanto por los grupos de trabajo específicos establecidos cada año, como por el Comité de Seguimiento del Plan 
de Acción de ABAC (APMC, por sus siglas en inglés).

Durante el año 2000, ABAC centró su atención principalmente en las implicaciones de la globalización para APEC. Con este fin, los grupos de trabajo se abocaron ese año al reforzamiento de los sistemas financieros nacionales, a la ampliación de los mecanismos de acceso a la tecnología y a la facilitación de la inversión. El papel del APMC es precisamente monitorear e impulsar los avances de APEC con respecto a sus propias metas de libre comercio e inversión dentro de la región, las cuales se establecieron en 1994 mediante los Acuerdos de Bogor, Indonesia, y que fijaron como plazo el año 2010 para las economías desarrolladas y el 2020 para aquellas en desarrollo con objeto de completar estos procesos. De igual forma existe un comité informal de miembros de ABAC, centrado en los intereses específicos de las pequeñas y medianas empresas, el cual participa en cada reunión de ésta y sus puntos de vista son tomados en cuenta en las actividades de los grupos de trabajo y del APMC.

Quizás el momento más significativo de ABAC es el diálogo anual que sostiene con los líderes de APEC, el cual tiene lugar durante la reunión cumbre de este organismo a finales de cada año. Este diálogo anual representa la oportunidad, única para los líderes de APEC y los líderes empresariales, para discutir y acordar medidas de interés común. El apoyo administrativo para el programa de trabajo de ABAC es proporcionado por el director ejecutivo y el director de operaciones del mismo, quienes encabezan el secretariado internacional de ABAC, actualmente a cargo de Filipinas.

Durante el año 2000, hubo cuatro reuniones de ABAC: en febrero se llevó a cabo en Tailandia, en mayo en China, en agosto en Perú y en noviembre en Brunei.

\section{Estructura de ABAC}

Como parte de su estructura ABAC cuenta con un presidente, dos vicepresidentes, tres grupos de trabajo y dos comités, cada uno con tareas y actividades específicas.

- Presidente de ABAC 2001

Qin Xiao, Vicepresidente de China International Trust and Investment Corporation.

- Vicepresidente de ABAC 2001

Timothy Ong Teck Mong, Presidente de Asia Inc. Investments Holdings Ltd, Brunei Darussalam.

Javier Prieto de la Fuente, Vicepresidente de CEMEX Corporation, México.

- Grupo de Trabajo de Comercio e Inversión Presidente: Victor Fung, Hong Kong, China. Vicepresidentes: Michael Crouch, de Australia; Azman Hashim, de Malasia y Dryden Spring, de Nueva Zelanda.

- Grupo de Trabajo de Finanzas Presidente: David Murray, de Australia. Vicepresidentes: Sy Sternberg, de USA; Hernan Somerville, de Chile y Jeffery Koo, de Taiwan.

- Grupo de Trabajo de Tecnomogía Presidente: Paul Song, de USA. Vicepresidentes: Michio Naruto, de Japón y Younghoon David Kim, de Corea del Sur.

- Comité de Evaluación del Plan de Acción (APMC)

Presidente: Viphandh Roengpithya, de Tailandia.

Vicepresidente: John MacDonald, de Canadá; Thomas Arai, de Japón y Ernie Micek, de USA.

- Comité de Pequeñas y Medianas Empresas Presidente: Andrina Lever, de Canadá. Vicepresidente: Benigno Ricafort, de Filipinas.

\section{El grupo ABAC México}

En el caso de México, ABAC está integrado por el Ing. Javier Prieto de la Fuente, Vicepresidente 
de Relaciones Exteriores de Grupo CEMEX y Presidente de la Cámara Nacional de Productores de Cemento; el Lic. Julio A. Millán Bojalil, Presidente y Director Ejecutivo de Coraza Internacional, S.A. de C.V.; y el Dr. Luis Téllez Kuenzler, Vicepresidente de Grupo Desc S.A. de C.V.

El Ing. Prieto de la Fuente, además de Presidente de ABAC México, es Presidente del Comité Mexicano del Consejo Económico de la Cuenca del Pacífico (PBEC, por sus siglas en inglés), asimismo es el responsable de la coordinación de las relaciones tanto con funcionarios gubernamentales como con empresarios e instituciones educativas, entre las cuales están la Federación Interamericana de Productores de Cemento, el Consejo Nacional de Comercio Exterior y la Asociación de Productores de Cemento del Caribe. También es consejero de diversas organizaciones asistenciales de Monterrey, México, y presidente y fundador de SELIDER, organización que promueve el liderazgo juvenil.

El Lic. Millán Bojalil es Presidente Emérito del Comité Mexicano de PBEC, organismo en el que también ha sido vicepresidente. Ha sido Presidente del Área de Asia y Oceanía del Consejo Empresarial Mexicano, incluidas las secciones mexicanas de los comités bilaterales establecidas con Japón, Corea del Sur, la República Popular China y Hong Kong. Es también presidente de la junta de directores de Consultores Internacionales, S.C., y de Banco de Tecnologías, S.A. de C.V., fue Vicepresidente de Olivetti Mexicana, S.A. de C.V., miembro de diferentes organizaciones como el Consejo Mexicano de Comercio Exterior, miembro activo de asociaciones y fundaciones sociales y director de diversas universidades.

En 1987, el Lic. Millán Bojalil fue distinguido por el gobierno japonés con la Orden Imperial del Sol Naciente, por su contribución al desarrollo de las relaciones económicas entre
México y Japón. En marzo de 2000, recibió el reconocimiento como ejecutivo del año en comercio exterior que el Instituto Mexicano de Comercio Exterior otorga al empresario más reconocido en este campo. Recientemente le fue conferida por el gobierno italiano la condecoración "Orden al Mérito de la República Italiana en Grado de Comendador".

Por su parte, el Dr. Téllez Kuenzler antes de pasar al sector privado, fue un prominente funcionario público. Fue Director General de Planeación Fiscal de la extinta Secretaría de Programación y Presupuesto (SPP), Subsecretario de Planeación de la Secretaría de Agricultura y Recursos Hidráulicos (SARH) en 1990 y Secretario de Energía en 1997, destacándose por su activa participación, junto con la Organización de Países Exportadores de Petróleo (OPEP), para estabilizar el mercado mundial de petróleo.

Sin lugar a duda el pricipal reto para estos tres empresarios mexicanos integrantes de ABAC México, será conjuntar sus esfuerzos y su amplia experiencia en el sector público y privado para impulsar, de manera efectiva, una participación más activa del empresariado mexicano y, con ello, aprovechar mejor las múltiples oportunidades de negocios que brinda APEC a nuestro país. La organización de APEC 2002 en México representa una invaluable oportunidad en ese sentido, además de fomentar nuestras relaciones comerciales con los países de esa región.

\section{Fuentes}

http://www.apec2002.org.mx, http://www.abaconline.org/ aboutus/default.htm TI:- 